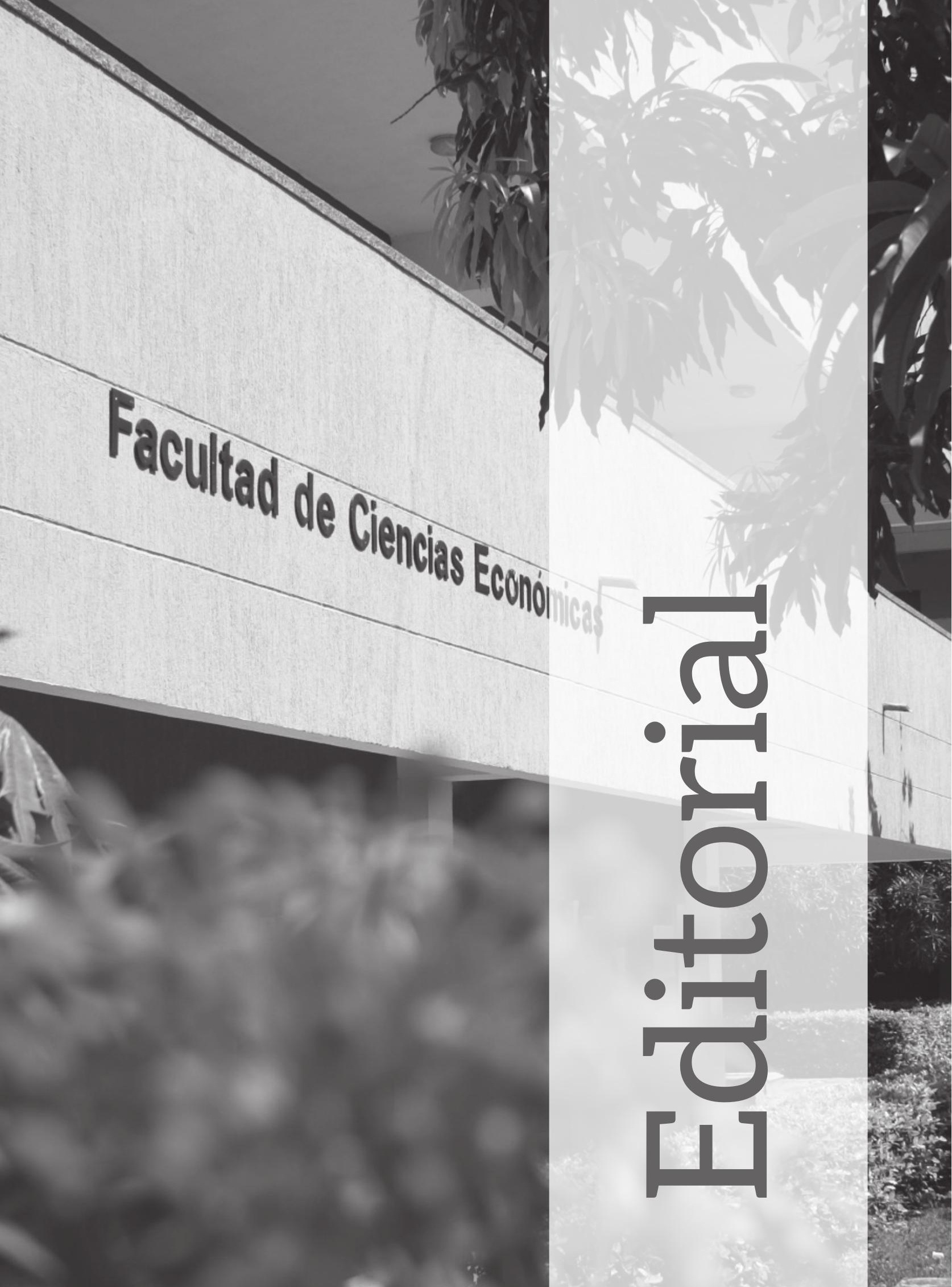





\title{
Publindex y el impacto de las publicaciones científicas nacionales
}

\author{
Andrés Escobar-Espinoza* \\ Colombia \\ Bernardo Romero** \\ Colombia
}

La Política Nacional para Mejorar el Impacto de las Publicaciones Científicas Nacionales establece una serie de estrategias y acciones orientadas al fortalecimiento de las publicaciones a nivel nacional, teniendo en consideración estándares de calidad editorial y científica en términos de su impacto. Es por ello que el Departamento Administrativo de Ciencia, Tecnología e Innovación (Colciencias) definió el nuevo Modelo de Clasificación de Revistas Científicas Nacionales en el año 2016, que contempla importantes avances y ajustes con relación al proceso de indexación de dichas publicaciones.

La implementación del nuevo modelo contemplo dos etapas: una primera orientada a la realización de un diagnostico preliminar, y una segunda o clasificatoria. En ambos casos, estas consideraron 3 fases de evaluación: a) Declaración de cumplimiento del proceso de gestión editorial; b) Validación del proceso de evaluación y de la visibilidad; y c) Evaluación del impacto de la revista científica nacional (Colciencias, 2017).

En este sentido, los resultados de la etapa diagnostica indicaron que se presentaron 604 revistas científicas en el proceso voluntario de las cuales 100 fueron clasificadas:

\begin{tabular}{|c|c|c|c|c|c|c|}
\hline ETAPA & $\begin{array}{c}\text { REVISTAS } \\
\text { REGISTRADAS }\end{array}$ & $\begin{array}{c}\text { REVISTAS } \\
\text { CATEGORIZADAS }\end{array}$ & A1 & A2 & B & C \\
\hline Diagnóstico & 604 & 100 & 0 & 8 & 42 & 50 \\
\hline $\begin{array}{c}\text { Clasificación } \\
\text { Resultados } \\
\text { Preliminares }\end{array}$ & 627 & 216 & 1 & 14 & 23 & 35 \\
\hline $\begin{array}{c}\text { Clasificación } \\
\text { Resultados } \\
\text { Finales }\end{array}$ & 627 & 244 & 1 & 14 & 104 & 125 \\
\hline
\end{tabular}

\footnotetext{
* Editor-Revista Panorama Económico de la Universidad de Cartagena. Correo de contacto: aescobare@unicartagena.edu.co

** Asistente Editorial - Revista Panorama Económico de la Universidad de Cartagena. Correo de contacto: bromero@unicartagena.edu.co
} 
Los anteriores resultados muestran que frente a los nuevos lineamientos establecidos a nivel nacional, las instituciones editoras deben fortalecer sus procesos editoriales, la visibilidad internacional y el impacto de las publicaciones que editan. Gran parte de las revistas científicas nacionales (cerca del 39\%) no cumplen con los nuevos criterios anteriormente señalados. Las nuevas exigencias implican no solamente un mayor compromiso institucional sino que también exige que la Política Nacional para el Fortalecimientodelas Publicaciones Científicas contempleun procesodeacompañamiento en miras a la internacionalización de las revistas científicas nacionales a partir de los resultados alcanzados en la última clasificación. Por otro lado, aproximadamente el $60 \%$ de las publicaciones nacionales que participaron cuentan con procesos claros de gestión editorial y sobre todo, impacto científico a partir del índice de Hirsch (Hirsch, 2005), lo que denota que los procesos editoriales a nivel nacional han mejorado paulatinamente y que las publicaciones seriadas nacionales son consideradas como referencias en diversos círculos académicos (teniendo en cuenta las métricas citacionales).

La labor desarrollada por la Revista Panorama Económico, responden a estos nuevos lineamientos y permitieron su clasificación a nivel nacional en la categoría B del IBN de Publindex (Escobar \& Angulo, 2015; Escobar \& Lopez, 2016; Escobar \& Mercado, 2014). Con miras a la internacionalización de la misma, las nuevas dinámicas globales de publicación científica requieren un mejoramiento sustancial en los formatos electrónicos de publicación, la disponibilidad de los contenidos publicados en varios idiomas, agilidad en los procesos editoriales (frecuencia de publicación), fortalecimiento del equipo editorial, parámetros claros de ética e integridad científica, e incluso contemplar la sostenibilidad financiera de la misma.

\section{REFERENCIAS BIBLIOGRÁFICAS}

Departamento Administrativo de Ciencia, T. e. (12 de Septiembre de 2017). Colciencias. Recuperado el 01 de Diciembre de 2017, de https://www.colciencias.gov.co/sites/default/files/informeresultados-publindex.pdf

Escobar, A., \& Angulo, G. (2015). Panorama Económico en el marco de la visibilidad internacional de las revistas cientificas. Panorama Económico, 23, 7-9.

Escobar, A., \& Lopez, N. (2016). Visibilidad internacional de la Revista Panorama Económico. Panorama Económico, 24, 7-9.

Escobar, A., \& Mercado, M. (2014). The Colombian Scientific Journals and Colciencias' public policy. Panorama Económico, 22, 7-9.

Hirsch, J. E. (2005). An index to quantify an individual's scientific reserch output. Proceedings of the National Academy of Sciences PNAS, 102(46), 16569-16572. 